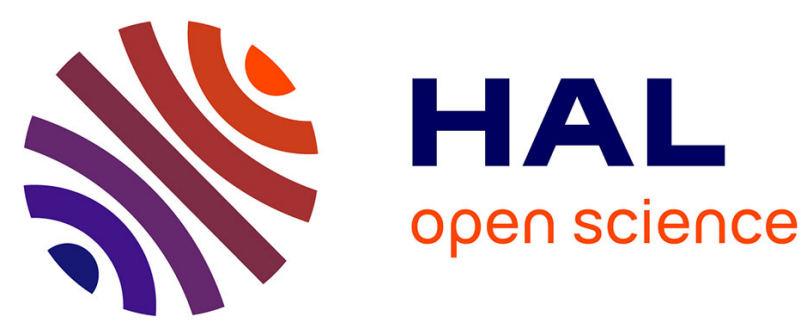

\title{
Knowledge-Based Geo-Risk Assessment for an Intelligent Measurement System
}

\author{
T. Vicovac, A. Reiterer, U. Egly, T. Eiter, D. Rieke-Zapp
}

\section{To cite this version:}

T. Vicovac, A. Reiterer, U. Egly, T. Eiter, D. Rieke-Zapp. Knowledge-Based Geo-Risk Assessment for an Intelligent Measurement System. Third IFIP TC12 International Conference on Artificial Intelligence (AI) / Held as Part of World Computer Congress (WCC), Sep 2010, Brisbane, Australia. pp.215-224, 10.1007/978-3-642-15286-3_21 . hal-01058358

\section{HAL Id: hal-01058358 \\ https://inria.hal.science/hal-01058358}

Submitted on 26 Aug 2014

HAL is a multi-disciplinary open access archive for the deposit and dissemination of scientific research documents, whether they are published or not. The documents may come from teaching and research institutions in France or abroad, or from public or private research centers.
L'archive ouverte pluridisciplinaire HAL, est destinée au dépôt et à la diffusion de documents scientifiques de niveau recherche, publiés ou non, émanant des établissements d'enseignement et de recherche français ou étrangers, des laboratoires publics ou privés.

\section{(c)(1)}

Distributed under a Creative Commons Attribution| 4.0 International License 


\title{
Knowledge-Based Geo-Risk Assessment for an Intelligent Measurement System
}

\author{
T. Vicovac ${ }^{1}$, A. Reiterer ${ }^{1}$, U. Egly ${ }^{2}$, T. Eiter $^{2}$ and D. Rieke-Zapp ${ }^{3}$ \\ ${ }^{1}$ Institute of Geodesy and Geophysics, Research Group Engineering Geodesy, \\ Vienna University of Technology, Gusshausstraße 27-29, 1040 Vienna, Austria. \\ ${ }^{2}$ Institute of Information Systems, Research Group Knowledge-Based System, \\ Vienna University of Technology, Favoritenstraße 9-11, 1040 Vienna, Austria. \\ ${ }^{3}$ Institute of Geological Sciences, Research Group Exogene Geology, \\ University of Bern, Baltzerstrasse 1+3, 3012 Bern, Switzerland. \\ \{tanja.vicovac, alexander.reiterer\}@tuwien.ac.at, \{uwe, eiter\}@kr.tuwien.ac.at, \\ zapp@geo.unibe.ch
}

\begin{abstract}
Rockfalls and landslides are major types of natural hazards worldwide that kill or injure a large number of individuals and cause very high costs every year. Risk assessment of such dangerous events requires an accurate evaluation of the geology, hydrogeology, morphology and interrelated factors such as environmental conditions and human activities. It is of particular importance for engineers and geologists to assess slope stability and dynamics in order to take appropriate, effective and timely measures against such events. This paper presents a decision-tool for geo-risk assessment on the basis of a knowledge-based system. The integration of such a tool with novel measurement sensors into an advanced system for geo-risk monitoring, which performs data fusion on-line, is innovative. To enable such a system, a knowledge base capturing domain knowledge formally is developed, which to the best of our knowledge is unprecedented; the completed part for initial risk assessment works quite well, as extensive experiments with a number of human experts have shown.
\end{abstract}

Keywords: Knowledge-Based System, Alerting System, Rockfall and Landslide Monitoring.

\section{Background and Motivation}

In the last years, damage caused by rockfalls and landslides has been increasing, as well as the number of persons that were killed or injured, due to a spread of settlements in mountain areas. In addition, many global climate change scenarios predict an increase in the probability of heavy rain, which is a primary trigger for rockfalls and landslides. This causes an urgent need for highly effective and reliable tools for monitoring rockfalls and landslides at an operational level. The increasing 
importance of rockfall and landslide monitoring is clearly also reflected by a large number of research projects. For example, in its last two framework programs, the European Commission has positioned research about "Natural Hazards" and "Disaster-Management" as a priority topic. The core of geo-risk management consists of identifying, understanding and mitigating risk by reducing the probability or consequences of rockfalls and landslides. In the literature, several geo-risk management and geo-monitoring systems can be found; most notable are $[5,10,11$, 13, 14]. Examples for systems used in practice are GOCA [7] and GeoMoS [6]. The main application field of these tools is monitoring and analyzing deformations; however, they offer no possibility for deformation interpretation. Currently this is done by human experts from geology and civil engineering, who are interpreting deformations on the basis of a large number of data records, documents and knowledge of different origin.

Given the increasing number of problematic sites and the limited number of human experts, automated intelligent monitored interpretation systems are required. The implementation of a knowledge-based system enables an automatic process of interpretation and determining of the risk potential. In contrast to the mentioned monitoring tools (e.g., GOCA), it is possible to perform deformation interpretation with our system. Based on the measured deformation vectors, a measurement preprocessing is performed (mainly clustering to detect areas of similar movement). On the basis of this information and additional data about velocity and orientation, some conclusions about the kind of occurring movement can be drawn. Additionally, data of different, heterogeneous sources, such as geodetic deformation measurements, geotechnical measurements, geological maps, geomorphological maps, in-situ investigations, and numerical modeling methods have to be included in such a system.

It should be emphasized that the integration of a knowledge-based system for solving this task represents an innovative method.

At the Vienna University of Technology (Institute of Geodesy and Geophysics), the interdisciplinary research project $i-M e a S$ ("An Intelligent Image-Based Measurement System for Geo-Hazard Monitoring") [8] has been launched with the purpose of research, develop and implement an interpretation tool for geo-risk objects. The system gives on-line information about ongoing deformations and supports issuing alerts in case of excessive deformation behavior.

Making conclusions about incidents is a not-trivial problem; by using artificial intelligence techniques, via the integration of a knowledge-based system, new directions are opened up. Such decision systems are currently used in medicine [2] as well as image mining [1]. This new system is a complex intelligent system, working with several different data sets in real-time. Deformation measurement data will be delivered by a novel type of measurement system, which consists of two image-based sensors. Inside the captured images so-called interest points are detected. The calculation of the $3 \mathrm{D}$ coordinates is done by classical geodetic forward intersection ${ }^{1}$. By means of such a high precision measurement system, 3D object points can be detected with an accuracy of about 2-3 $\mathrm{mm}$ (object distances up to $1000 \mathrm{~m}$ ).

\footnotetext{
${ }^{1}$ Forward intersection is a standard method for determining 3D object coordinates from 2D image points.
} 
Subsequently a geodetic deformation analysis can be performed that yields as a result deformation movement vectors, which constitute the input for later interpretation.

In this paper, we report on the architecture and functionality of the respective interpretation system and its development stage. In particular, we present a knowledge base for risk assessment, which to the best of our knowledge is unprecedented, and as comparative tests with a number of domain experts indicate, works well compared to human experts.

\section{System Concept and Architecture}

Remote monitoring of unstable slopes is a typical multidisciplinary problem incorporating a network of sensors of different kinds. Movements and deformations can be measured, for instance, with geo-technical sensors (e.g., inclinometers, tiltmeters, extensometers, etc.), or optical measurement systems (e.g., tacheometers, laser scanners, etc.). Most of these sensors must be placed on-site; in hazardous terrain this is very often not possible. It is thus also necessary to apply remote monitoring methods, some of which are based on photogrammetric methods or terrestrial synthetic aperture radar (SAR). Both yield multi-temporal images that contain distances to the scene in each pixel.

Current Systems. Recently, the interest in image-based measurement systems has increased. Leica Geosystems [16] developed a prototype of an "image-assisted total station" with the purpose of defining a hybrid or semi-automatic way to combine the strength of the traditional user-driven surveying mode with the benefits of modern data processing. Furthermore, Sokkia [15] introduced a prototypical tacheometer which provides focused color images.

The central task of all image-based deformation measurement systems is the calculation of 3D object coordinates from 2D image coordinates for a subsequent deformation analysis or object reconstruction. The basic idea of deformation measurements is capturing a zero state of the object (measurement epoch 0) and one or more subsequent object states (measurement epoch $n$ ). The time interval between the measurements depends on the type and the estimated behavior of the objects.

All these measurement systems are based on a permanent user interaction. Selection, pointing and measurement of the relevant object points have to be operated by a measurement expert. Most of the relevant processing steps are fully manual. The challenging task of the mentioned $i$-MeaS project is to develop a fully automated system (user interaction will be possible at different decision levels). Data capturing, data analysis and data interpretation should be performed as an automated process.

System Concept. In our system, we are using a new kind of optical measurement system which is based on a traditional tacheometer system ${ }^{2}$, namely an image-based tacheometer system. In comparison with laser scanners, this system measures objects with higher accuracy; compared to photogrammetric systems, they are easier to use for on-line measurement processes (e.g., object monitoring), especially because measurements can be done with a high degree of automation.

${ }^{2}$ A tacheometer is a surveying instrument for distance determination and measurement of horizontal and vertical angles. 
The processing chain of the new measurement concept starts with the capturing of geo-referenced images, followed by image point detection and by $3 \mathrm{D}$ point measurement. The final output of this measurement process is a list of 3D deformation vectors of the object (deformations captured between two or more measurement/time epochs). Measurement data is one of the basic elements of decision-making - however, many other factors are used by the system (more details are given below). The system architecture can be divided into several components:

- the measurement sensors (e.g., geodetic, geotechnical and on-site placed meteorological sensors),

- an image analysis system (which is needed because some sensors are working on the basis of captured images),

- a system control component,

- a knowledge base,

- a system for deformation analysis, and

- a system for alerting.

Furthermore, the system includes an user interface. The simplified architecture of the system, with the knowledge base and the system control component as core units, is shown in Fig. 1. A description of the measurement system can be found in [8].

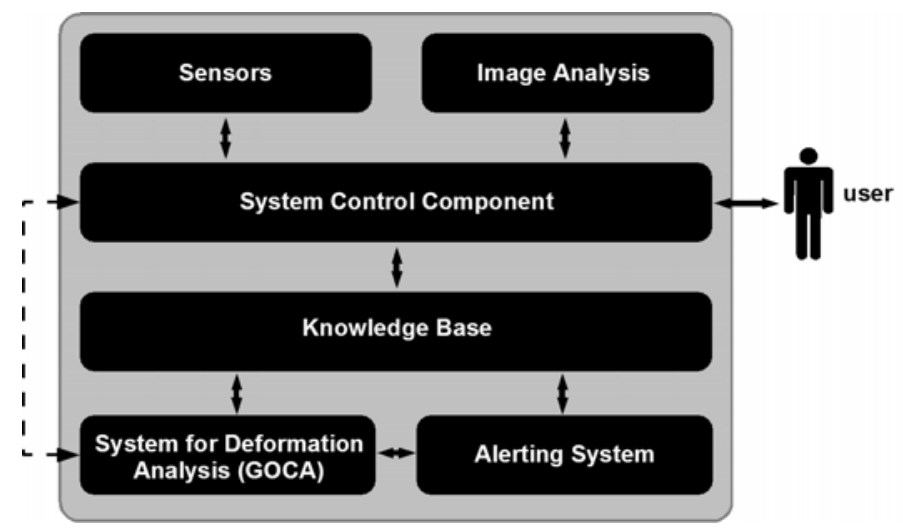

Fig. 1. Simplified architecture of the system.

As mentioned above, such a complex system works on the basis of heterogeneous information. We are using the following information sources:

- generic domain knowledge (i.e., knowledge about coherences of influence factors and general deformation behavior),

- $\quad$ case-specific knowledge (i.e., domain knowledge collected via historical notes, morphological and geological maps), measurement data (geodetic, geotechnical, geophysical measurement data, etc.),

- local weather data (like local temperature, the amount of precipitation, the kind of precipitation, etc.), and

- $\quad$ global meteo data, which are provided by meteorological services. 
In order to test the optical measurement system under realistic field conditions the sensor system was installed over several days on the "Pasterze" glacier, the largest glacier in the Eastern Alps. The end of the glacier which is covered by debris and a geologically stable rock face was chosen as test site. The main purpose of the test was the evaluation of the point detection and the consecutive calculation of 3D coordinates under realistic environmental (especially illumination) conditions. The results show that the measurement system works very well and moreover could measured 3D object coordinates with an accuracy of 2-3 $\mathrm{mm}$ (the distance to the object was about $1,000 \mathrm{~m})$.

\section{Risk Assessment}

As mentioned above, there is a high demand for reliable prediction of hazardous events. Apart from monitoring, the detection of possible causes is a matter of particular interest. According to these preconditions the requirements on a geo-risk assessment system are quite high. Eventually, knowledge-based interpretation should be able to draw conclusions about the type of occurring movements as well as providing possible causes for them.

The concept of data interpretation is based on the "calculation" of risk factors for critical cause variables and on the elaboration of an interpretation for the deformation. Examples for cause variables can be precipitation, permafrost, critical slope angle, etc. The range value of the risk factor is divided into six classes (low, low-medium, medium, medium-high, high, very-high). This definition is based on the discussion results with experts.

The challenging problem in developing such an alerting system is (1) to identify relevant factors and (2) subsequently to capture the interlinkage of these influence factors. The latter are described in the next section.

In our system, the process of risk assessment is divided into two steps: (1) the determination of the "Initial Risk Factor" and (2) the determination of the "Dynamic Risk Factor". The first step estimates the plausibility of an occurring moving event. Furthermore the zero state of interpretation and the observation is defined.

The second step is focused on the processing of the temporal development of the risk factor. Therefore additional data have to be included into the decision process, e.g., measured data captured by the image-based monitoring system. Measurement data represent the 3D object deformations (data is captured in defined time periods resulting in movement/displacement vectors). As mentioned above, the system is also able to access local and global meteo data in real-time, which can be used by the dynamic system as a basis for deformation prediction.

This process is leading to a detailed description of the deformation and an actual estimation of the risk factor, standardized on a predefined scale, which can be directly used as a global indicator for the likelihood that a landslide or a rockfall will occur.

In practice, the estimation of the risk factor is a continuous process, in which the dynamic risk factor has to be determined in a periodic feedback cycle.

In the following, we focus on the determination of the "Initial Risk Factor". Beside difficult technical requirements related to sensor and data fusion, the most challenging 
tasks in developing such a system is the implementation of the knowledge base and, in a preliminary step, the knowledge acquisition. This problem was solved using a two-step approach: in the first step, a single expert was consulted, while in the second step an extensive system evaluation by many experts was carried out and their feedback was incorporated into a system refinement (details are given below).

\section{Construction of the Knowledge Base}

As described, the challenging problem is the realization of the knowledge-based part, especially the acquisition of knowledge from human experts. For this, we adopted a common methodology $[3,12]^{3}$. In order to estimate the initial risk factor, influence factors had to be identified whose values increase the likelihood of deformation. During a period of extensive discussions about the domain problem, more than thirtyfive relevant influence factors were identified (e.g. vegetation, granual material, subsoil, pieces of rock, indicates, slope angle, slope profile, slip surface, material underground, saturation of soil, leaning trees, leaning rocks, crack, rock joint, joint orientation, insolation, permafrost, stone chips, frost-thaw-cycle, depth of movement, local temperature, etc.). About thirty of them are used for the determination of the "Initial Risk Factor". Some factors including examples for possible consequences are listed in Table 1.

Table 1. Examples for influence factors for the initial risk factor and possible consequences.

\begin{tabular}{|l|l|}
\hline Influence Factor & \multicolumn{1}{|c|}{ Examples for Consequences } \\
\hline vegetation & $\begin{array}{l}\text { The vegetation has an influence on the slope stability and soil } \\
\text { saturation. }\end{array}$ \\
\hline granual material & $\begin{array}{l}\text { In interaction with slope angle and the kind of subsoil a conclusion } \\
\text { about the slope stability can be done. }\end{array}$ \\
\hline slope angle & $\begin{array}{l}\text { In interaction with slope angle and the kind of subsoil a conclusion } \\
\text { about the slope stability can be done. }\end{array}$ \\
\hline slip surface & Existing slip surfaces are an indicator for slope movements. \\
\hline soil saturation & The degree of saturation is dependent on the vegetation on the surface. \\
\hline leaning trees / rocks & Leaning trees and rocks are indicators for slope movements. \\
\hline insolation & $\begin{array}{l}\text { Insolation can affect factors like soil saturation and in combination with } \\
\text { the influence caused by granual material and slope angle a conclusion } \\
\text { about the slope stability can be done. }\end{array}$ \\
\hline permafrost & $\begin{array}{l}\text { The existence or absence of permafrost has an influence on the slope } \\
\text { stability. }\end{array}$ \\
\hline
\end{tabular}

On the basis of the identified factors and the discussion, we have developed an onlinequestionnaire, which serves as a makeshift for assessing the "Initial Risk Factor" of the object to be observed. The questionnaire comprises questions ranging from the geological and morphological characterization, the vegetation, and the hydrology of the mountainside to administrative issues. The expert may answer all object-relevant questions in-situ/online, usually using multiple sources to find the answers; geological and geomorphological maps, historical documents, data of earlier geotechnical or

${ }^{3}$ Currently we are using no automated knowledge acquisition methods - for the future the use of such methods is envisaged. 
geodetic measurements of the observed slope, and last but not least inspection of the endangered area.

Discussions with several experts revealed that estimating a risk factor on the basis of many influence factors and extensive domain knowledge is highly complicated. Moreover, experts sometimes largely disagree. Thus, a system which incorporates the opinion of more than one expert is indispensable to guarantee continuous high-level quality of decisions.

For estimating the mentioned risk factor, we developed a knowledge-based system, adopting a rule-based approach, more specifically using production rules. This is because the connection between influence factors and possible causes or deformation behavior can be naturally formulated by rules, and this representation is more accessible to domain experts than other representations.

For the implementation, we have chosen JESS [4, 9], which is a rule engine and scripting environment entirely written in JAVA. JESS is easy to learn and use, is well documented and supported; moreover it supports fuzzy rules and uncertainty. Furthermore JESS integrates well into the Eclipse software development environment which is widely used in industry.

In order to make the collected numerical features (like measurement data, meteorological data, etc.) more suitable for the rule-based decision system, we use an abstraction procedure that is in line with the expert view. It translates the numerical input values (image features) into linguistic concepts which are represented by abstraction ("fuzzy") sets. More specifically, they form an ordinalization, i.e., the sets are characterized by non-overlapping step membership functions; hence, this translation is a pre-stage of full fuzzification. The use of such an abstraction enables decision rules in terms of easily-understood word descriptors instead of numerical values. Furthermore, all data sets are synchronized by a common time basis.

An example of a simplified initial state rule (IS) (JESS syntax) is shown in the following. The LHS of the rule 'IS_riskpot_rockfall' checks whether there are elements of type IS ROCKFALL in the working memory, fact1 and fact2, where in factl certain slots (i.e., attributes) have certain values (danger_recent_deformation has value 'high', etc., and frost_thaw_cycle has value either 'NO' or 'NN'), and fact2 states that a risk factor is not defined. The RHS includes the instruction to update the status of fact2 to have risk_defined true and to set risk_pot to high_4. The values of the used slots (danger_recent_deformation, danger_slope angle, danger bedding, danger_fine_grit) are determined from combination of input elements (separated rules).

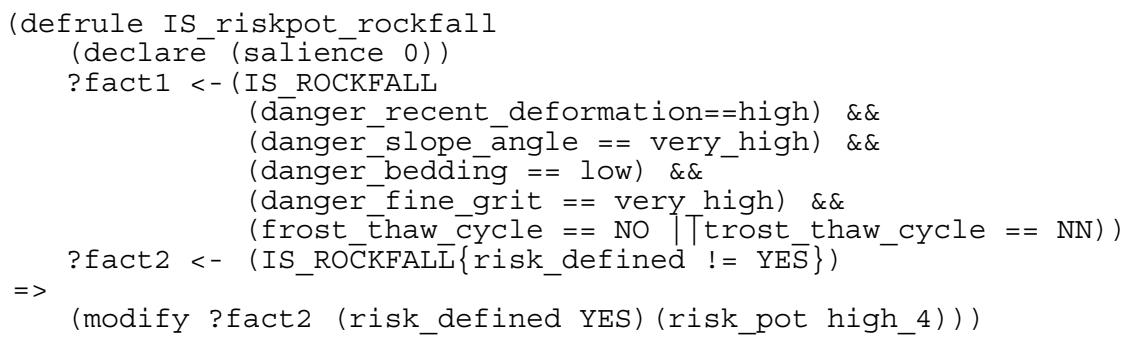


Generally, the rule base is divided into two groups of rules: (1) rules regarding the connections between facts and consequences (e.g., rain and the consequent possible deformation of the object), and (2) rules determining the initial risk factor. The mentioned example is part of the second group. The whole "initial-risk-factor-system" consists of about 70 rules. It is also notable that we have developed a tool for visualization of rules and their firings, which helps in grasp and analyzing data dependencies.

\section{Evaluation and Experiments}

After developing and implementing a prototype for determining the "Initial Risk Factor", we performed an evaluation in a two step approach: (1) evaluation by one expert, followed by an improvement of the system, and (2) an exhaustive evaluation by eight experts.

In step 1, 30 different data sets were prepared by one expert, where each data set models a test site with particular characteristics concerning slope profile, vegetation, insolation, etc. Facts like soil material, slope angle, hydrological properties, information about indicates for movement, etc. were predetermined. Then, the system processed the data sets and the risk factors determined were compared with the decisions by the single expert. The discrepancies were analyzed and the explorations were used for extending and upgrading the prototype system.

In step 2, eight geological experts had to appraise independently the 30 test cases. The resulting risk factors were compared with the result of the prototype system. It is striking to note that the risk factor between the different experts varies up to two classes. In exceptional cases, the difference is more than three. A statistical overview of the differences $(\Delta)$ between the eight experts and the system is shown in Fig. 3.

Also at the level of the individual test cases, the answer conformity was high; it is remarkable that about $42 \%$ of the answers agree completely with the system, and $30 \%$ of the answers are at distance 1 . For example, expert 1 agrees completely with the system decision in 18 test cases $(\Delta=0)$, in ten test cases the decision has distance 1 and in two cases it has distance 2. From case to case even the disagreement between the experts can be quite high. This mainly depends on the individual experience and appraisal of each expert. For all the test case, there was 102 times complete agreement $(\Delta=0)$ of the experts and the system, while the maximal disagreement $(\Delta=4)$ was in 3 cases only.

The answers of the system and the experts completely agree in one case, and they span an interval of $i$ classes, $\mathrm{i}=1,2,3,4,5$, in 4,7,13,5 and 0 cases, respectively. Only in one case, the system answer is outside the interval of the expert answers. Furthermore, in 15 cases (i.e. 50\%) the system answer is the median of the expert answers and in 8 cases $(27 \%)$ one of the middle answers (e.g., in case 6 the system answer is 2, while the middle answers in the sorted expert answers 1,1,1,1,2,2,3,4 are 1 and 2 , thus the median is 1.5$)$; in 5 cases $(17 \%)$, it is one class to the median, and only in 2 cases the discrepancy is higher, with a maximum of two classes in the outlier case. 


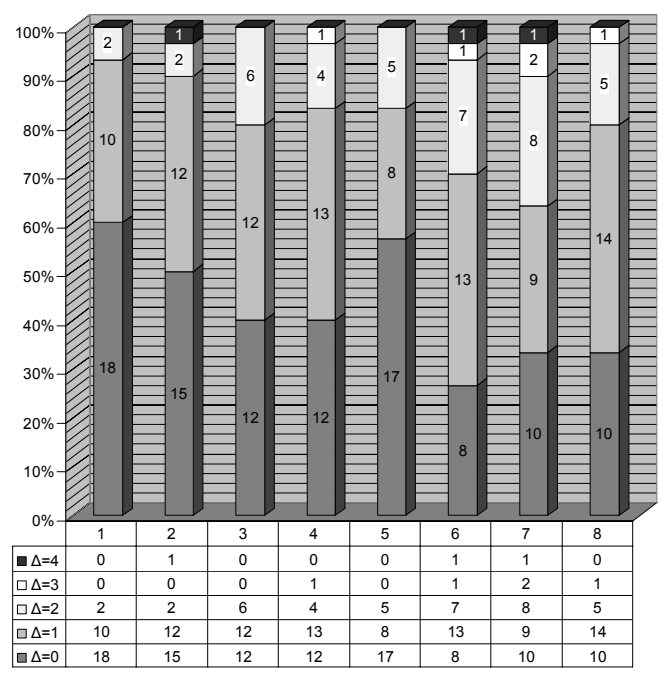

Fig. 2. Statistic overview of the processed expert evaluation.

As the above statistical data indicates, the risk assessment is a difficult task where expert experience is required to obtain a reasonable solution. This is witnessed by the fact that there is no sole "correct" assessment for many of the different test cases, and expert opinions on the risk can vary for the same test case. The system can compete with the human experts; the differences between the result of the system on one side and the experts' results vary in a similar way as the results vary between different experts. In order to further improve the quality of risk assessments of the system and to test its usability, we initiated an even broader evaluation where we asked additional experts for their opinion on our test cases. These new experts should bring in a fresh sight on the problem and the system because they have no information about the system and no training on it. The results obtained from first new probands are in accordance with the system and with the former evaluators. This also shows that the system interface is intuitive enough such that an untrained expert can easily use it without major difficulties.

\section{Conclusion}

The main goal of the presented work is the development of an innovative automated knowledge-based interpretation system for predicting rockfalls and landslides with advanced measurement techniques. Towards this goal, we have carried out extensive knowledge acquisition and performed knowledge analysis with the help of several experts, leading to a rich knowledge base that builds on a number of influence factors, determined from various information sources (e.g., measurement data, expert knowledge, maps, etc.).

An experimental prototype for risk assessment we developed shows good results for the completed "Initial Risk Factor" part, in where it behaves like a human expert. 
Currently, the dynamic system (the second part of the final system) is under development - besides extending the existing rule set, further rule components (e.g., for updating risk factor, including meteorological data, etc.) will be added. Future work will include testing (collecting field data is targeted for the summer of 2010) and the integration of the knowledge base component into an on-line geo-risk management system.

\section{Acknowledgments}

The research presented in this paper has been supported by the Austrian Science Foundation (FWF) Project L514 “ $i-M e a S-$ An Intelligent Image-Based Measurement System for Geo-Hazard Monitoring”.

\section{References}

1. Agrawal R., Mannila H., Srikant R., Toivonen H., Verkamo I.: Fast Discovery of Association Rules. In: Advances in Knowledge Discovery and Data Mining, MIT Press, Cambridge, pp. 229-248 (1996)

2. Clarke K., O’Moore R., Smeets R., Talmon J., Brender J., McNair P., Nykanen P., Grimson J., Barber B.: A Methodology for Evaluation of Knowledge-Based Systems in Medicine. Artificial Inteligence in Medicine, Vol. 6, Issue 2, pp. 107-121 (2004)

3. Farrand, P., Hussain, F., Hennessy, E.: The Efficacy of the Mind Map Study Technique. Medical Education, 36(5), pp. 426-431 (2002)

4. Friedmann-Hill, E.: JESS in Action. Rule-Based Systems in Java. Manning (2003)

5. Fujisawa, K.: Monitoring Technique for Rock Fall Monitoring. Internal Report (2000)

6. GeoMoS, http://www.leica-geosystems.com

7. GOCA, http://www.goca.info

8. i-MeaS, http://info.tuwien.ac.at/ingeo/research/imeas.htm

9. JESS, http://www.jessrules.com

10. Kahmen, H., Niemeier, W.: OASYS - Integrated Optimization of Landslide Alert Systems. In: Österreichische Zeitschrift für Vermessung und Geoinformation, 91, pp. 99-103 (2003)

11.McHugh, E.: Video Motion Detection for Real-Time Hazard Warning in Surface Mines. In: NIOSHTIC No. 20026093 (2004)

12.Negnevitsky, M.: Artificial Intelligence - A Guide to Intelligent Systems. 2nd Edition. Addison Wesley (2004)

13.Scaioni, M., Giussani, A., Roncoroni, F., Sgrezaroli, M., Vassena, G.: Monitoring of Geological Sites by Laser Scanning Techniques. IAPRSSIS, Vol. 35, pp. 708-713 (2004)

14.Scheikl, M., Poscher, G., Grafinger, H.: Application of the New Automatic Laser Remote System (ALARM) fort he Continuous Observation of the Mass Movement at the Eiblschrofen Rockfall Area - Tyrol. Workshop on Advances Techniques for the Assessment of Natural Hazards in Mountain Areas, Austria (2000)

15.Sokkia: http://www.sokkia.com

16.Walser, B., Braunecker, B.: Automation of Surveying Systems through Integration of Image Analysis Methods. In: Optical 3-D Measurement Techniques VI, Grün and Kahmen (Editors), Volume I, Zurich, pp. 191-198 (2003) 